\title{
The new era and paradigms for patient consent
}

\author{
Uma nova era e os novos paradigmas para consentimento esclarecido
}

Renato P. Munhoz

University of Toronto, Toronto Western Hospital, Movement Disorders Centre, Toronto, ON, Canada.

\section{Correpondence:}

Renato P. Munhoz; Morton and Gloria Shulman Movement

Disorders Centre and the Edmond

J. Safra Program in Parkinson's

Disease, Toronto Western Hospital,

399 Bathurst St. Toronto, ON, M5T

2S8, Canada;

E-mail: renatopuppi@yahoo.com

Conflict of interest:

There is no conflict of interest to declare.

Received 12 December 2016;

Accepted 19 December 2016

\section{(c) BY}

I $\mathrm{n}$ an ideal scenario, a patient / physician encounter should follow a natural flow from the collection of relevant clinical data, to diagnosis and proposal of therapeutic interventions. Hidden between the lines of these encounters, which are the routine for most professionals involved in clinical care, lies the need for patient consent and active decision-making for all health related procedures, including diagnosis, treatment and disclosure of pertinent information to "third parties" such as family members, care-givers, etc. On the one hand, the backbone of this spontaneous and elementary process consists of providing competent, unbiased and objective knowledge about the context and interpretation of the clinical question (i.e., symptoms, disease, etc.) and the proposed answer (diagnostic and/or therapeutic interventions). On the other hand, the other foundation of this art, from the physician's perspective, is to determine, in an occasionally time limited clinical setting, each patients ability to understand their own condition, the impact of proposed procedures and options for care. While this process may be made clear and straightforward in most instances, several circumstances may be particularly challenging as in, for example, the case of patients with limitations of alertness, mental status, and cognition. These and other similar conditions are inevitable and intrinsic part of the daily routine of neurologists, with an impact that transcends the medical facet of their work, permeating legal, moral, ethical, and cultural realms.

Unfortunately, our ability to make the correct judgment about patient's competency to accept or deny medical intervention is far from optimal. One study of a large group of patients with acute conditions found that almost half were not competent to consent to medical treatment, including patients with several conditions, the most common being neurologic and infectious diseases. The most concerning aspect of the study is that the clinical team responsible for these patients had identified only approximately one quarter as being unable to consente ${ }^{1}$.

In this issue of the Arquivos de Neuropsiquiatria, Santos et al. ${ }^{2}$ present their adaptation of the MacArthur Competence Assessment Tool (MacCAT-T) ${ }^{3}$ to Brazilian Portuguese, testing it in patients with Alzheimer's disease (AD). The MacCAT-T isMacCAT-T) is a tool focused on clinical assessment, successfully applied in patients with dementia, mild cognitive impairment, and psychiatric conditions. This instrument offers a flexible yet structured method with which health professionals can assess, rate and report the relevant abilities of competence to consent to treatment. Validation and cross-cultural adaptation of a complex tool such as the MacCAT-T is a long and laborious process that was obsessive and competently accomplished by the authors. Moreover, this form of adaptation requires semantic, conceptual and experiential equivalence to the original characteristics of the instrument.

Considering the ageing of our population and the widely acknowledged burden that certain age-related diseases are expected to play in our society, the fact that the authors specifically chose a cohort of cases of $\mathrm{AD}$ enlarges the importance and potential impact of this study for Brazilian health professionals involved in the care of these complex disorders. The Santos et al. study in this new era highlights the endless need to revisit and question seemingly established paradigms of care and particularly physician / patient interaction. 
1. Raymont V, Bingley W, Buchanan A, David AS, Harward P, Wessely S et al. Prevalence of mental incapacity in med-ical inpatients and associated risk factors: cross-sectional study. Lancet. 2004;364(9443):1421-7. doi:10.1016/S0140-6736(04)17224-3

2. Santos RL, Sousa MFB, Simões Neto, JP, Bertrand E, Mograbi DC, Landeira-Fernandez $J$ et al. MacArthur competence assessment tool for treatment in Alzheimer disease: cross-cultural adaptation. Arq Neuropsiquiatr. 2017;75(1):36-43.

doi:10.1590/0004-282X20160181

3. Grisso T, Appelbaum PS, Hill-Fotouhi C. The MacCAT-T: a clinical tool to assess patients' capacities to make treatment decisions. Psychiatr Serv.1997;48(11):1415-9. doi:10.1176/ps.48.11.1415 